\title{
Influence of respiratory variations on right ventricular function
}

\author{
JOHN L CAPLIN, WILLIAM D FLATMAN, * LORRAINE DYKE, * \\ MARTIN N WISEMAN, DUNCAN S DYMOND
}

From the Departments of Cardiology and *Nuclear Medicine, St Bartholomew's Hospital, London

SUMMARY Respiratory effort during inspiration, expiration, and the Valsalva manoeuvre changes right ventricular preload and afterload. On inspiration these changes should improve systolic emptying of a larger end diastolic volume and so increase the ejection fraction, whereas on expiration the reverse should be true. The resting right ventricular ejection fraction was measured by first pass radionuclide angiography with gold-195m (half life $30.5 \mathrm{~s}$ ) in 17 individuals at maximal inspiration and expiration and in eight at rest and during the strain phase (phase 2) of the Valsalva manoeuvre. The right ventricular ejection fraction was significantly lower during expiration than during inspiration. There were, however, no significant differences in bolus duration or right ventricular transit time. The Valsalva manoeuvre, in contrast, significantly increased the ejection fraction and also significantly prolonged both the bolus duration and right ventricular transit time. The conformation of the bolus curves during the Valsalva manoeuvre suggested the development of tricuspid regurgitation.

These data suggest that relative influences of venous return, pulmonary arterial pressure, pulmonary vascular resistance, and possible functional tricuspid regurgitation vary during inspiration, expiration, and the Valsava manoeuvre and can affect the right ventricular ejection fraction. Changes in right ventricular function on exercise assessed by first pass radionuclide angiography must be interpreted with caution because maximal respiratory effort may alter the right ventricular ejection fraction independently of ischaemia or other non-ischaemic factors.

Recognition of the importance of right ventricular function ${ }^{1}$ has led to interest in its measurement. Radionuclide angiography is a safe, reproducible, and non-invasive method of assessing right ventricular ejection fraction. ${ }^{2-5}$ When the first pass method is used right ventricular transit lasts only a few seconds, and so rapid changes in function can be assessed. The use of the ultrashort half life radiopharmaceutical gold-195m allows multiple, rapid, sequential first pass radionuclide angiograms to be performed with a low radiation burden. ${ }^{6}$

During inspiration the negative intrathoracic pressure draws blood into the right atrium and so increases right ventricular filling pressure. ${ }^{7}$ In addition, the pulmonary vessels dilate as the lungs

Requests for reprints to Dr John L Caplin, Cardiac Unit, Southampton General Hospital, Southampton SO9 4XY.

Accepted for publication 11 April 1989 expand; thus pulmonary vascular impedance falls and this causes a fall in pulmonary artery pressure and hence right ventricular afterload. ${ }^{8}$ In contrast during expiration right ventricular filling pressure falls and afterload increases. Since the right side of the heart is a low pressure system, these changes in preload and afterload during respiration might be expected to bring about relatively large changes in right ventricular systolic function. During inspiration right ventricular filling and emptying will be enhanced, and since the ejection fraction is a ratio of the stroke volume divided by the end diastolic volume, it should increase. The converse is true during expiration.

The Valsalva manoeuvre, forced expiration against pressure, reduced pulmonary flow and increased pulmonary arterial pressure. ${ }^{9}$ An echocardiographic study suggested that right ventricular end diastolic volume falls during the Valsalva manoeuvre while stroke volume is maintained. ${ }^{10}$ If these data are correct and the systolic function of the right ventricle is enhanced during the Valsalva manoeuvre, then 
because blood is not pumped forward, functional tricuspid regurgitation must be responsible for maintaining or increasing right ventricular ejection fraction.

This study was designed to investigate the respiratory changes in resting right ventricular function during maximal inspiration, expiration, and the Valsalva manoeuvre.

\section{Patients and methods}

\section{PATIENTS}

We studied 25 people ( 22 men). They had been referred to the nuclear cardiology laboratory for the assessment of resting ventricular function. Most had proven or suspected coronary artery disease, but some were assessed for the possibility of a left ventricular aneurysm or cardiomyopathy. We excluded those who were unable to lie flat or were not in sinus rhythm. None had a history of asthma or chronic sputum expectoration or clinical evidence of pulmonary disease. Chest radiography showed no pulmonary abnormality and no one was taking bronchodilator or steroid medication. Informed consent was obtained for the study. No adverse effects were noted during the study.

\section{RADIONUCLIDE ANGIOGRAPHY}

First pass radionuclide angiography was performed as previously described. ${ }^{11}$ An 18 gauge cannula was inserted into a vein in the antecubital fossa and boluses of $15-20 \mathrm{mCi}(550-750 \mathrm{MBq})$ of gold-195m were injected by a rapid saline flush. Details of the portable mercury- $195 \mathrm{~m} /$ gold- $195 \mathrm{~m}$ generator and its validation for use in man have already been described. ${ }^{612}$ The subjects were imaged supine in the $30^{\circ}$ right anterior oblique projection, which produces the best spatial separation of right atrium and right ventricle. $^{13}$

\section{INSPIRATION AND EXPIRATION}

Before imaging the 17 subjects were instructed on taking and holding deep breaths, in and out. All subjects could hold their breath at maximal inspiration and expiration for at least 20 seconds. An initial injection was made to assess the time required for the bolus of radioactivity to pass through the circulation into the left ventricular phase, and the study proceeded only if this was less than $20 \mathrm{~s}$. Subjects were then imaged at maximal inspiration and then at maximal expiration. The appropriate respiratory manoeuvre was held for the entire duration $(20 \mathrm{~s})$ of the first pass study, and imaging of the right ventricle was therefore not obtained during a change from inspiration to expiration or vice versa. Three minutes ( $>5$ half lives) were allowed to elapse between each study.

\section{REST AND VALSALVA MANOEUVRE}

Eight subjects were instructed on how to perform a Valsalva manoeuvre (expiratory effort against a pressure) using a device specially designed to maintain an airway pressure of $\geqslant 35 \mathrm{~mm} \mathrm{Hg}$ (Medical Electronics Department, St Bartholomew's Hospital). All were able to maintain this pressure for at least $20 \mathrm{~s}$. Radionuclide angiography was performed at rest and then during the holding of the strain phase (also known as phase 2) of the Valsalva manoeuvre. ${ }^{14}$

\section{ANALYSIS OF DATA}

Right ventricular ejection fraction was calculated by a manual, iterative technique from high frequency time-activity curves derived from a right ventricular region of interest. ${ }^{15}$ An appropriate background correction was used. ${ }^{16}$ Right ventricular images were derived from background corrected end systolic and end diastolic images. Bolus duration was measured from the full width at half maximum of a timeactivity curve from a region of interest over the superior vena cava ${ }^{17}$ These curves were also analysed qualitatively for evidence of pulsatile flow, suggestive of tricuspid regurgitation (fig 1). A previous study showed that prolongation of the bolus has no significant effect upon the calculation of the right ventricular ejection fraction. ${ }^{15} \mathrm{We}$ derived the right ventricular transit time from the right ventricular time-activity curve, taking the first identified systolic frame (trough) as the beginning and the last diastolic frame (peak) as the end. The number of cycles available for analysis and the mean heart rate were also derived from the time-activity curve. Left ventricular function was not assessed because the left heart transit in first pass studies often came after the end of breath holding or the Valsalva manoeuvre (that is $>20 \mathrm{~s}$ after the injection). Thus in some studies it was impossible to be certain at which phase of the respiratory cycle the left heart was imaged.

\section{STATISTICAL ANALYSIS}

Statistical analysis was performed with a commercially available software program on a microcomputer. Inspiratory and expiratory results were compared by paired $t$ tests. Results are expressed as mean (SD).

\section{Results}

CHANGES FROM INSPIRATION TO EXPIRATION Figure 2 shows the response of the right ventricular ejection fraction from maximal inspiration to expiration in all individuals. The right ventricular ejection fraction on inspiration ranged from 12 to $48 \%$ with a mean value of $31 \cdot 8(11 \cdot 2) \%$. On expiration the range 

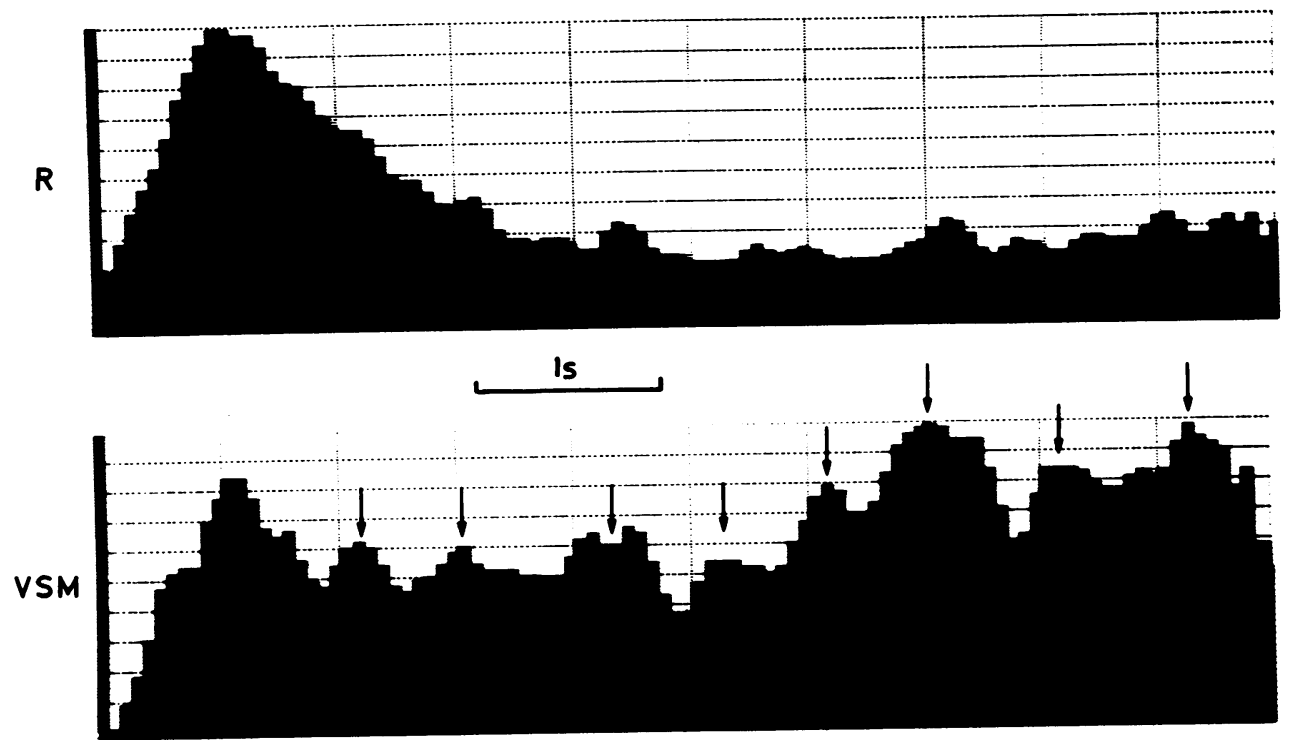

Fig 1 Representative time-activity curves, with counts on the vertical axis and time on the horizontal axis, from a region of interest over the superior vena cava. Upper curve at rest and lower curve during Valsalva manoeuvre. Note the considerable prolongation of the bolus duration and the appearance of pulsatile events (arrows) during Valsalva manoeuvre $R$, rest, VSM, Valsalva manoeuvre.

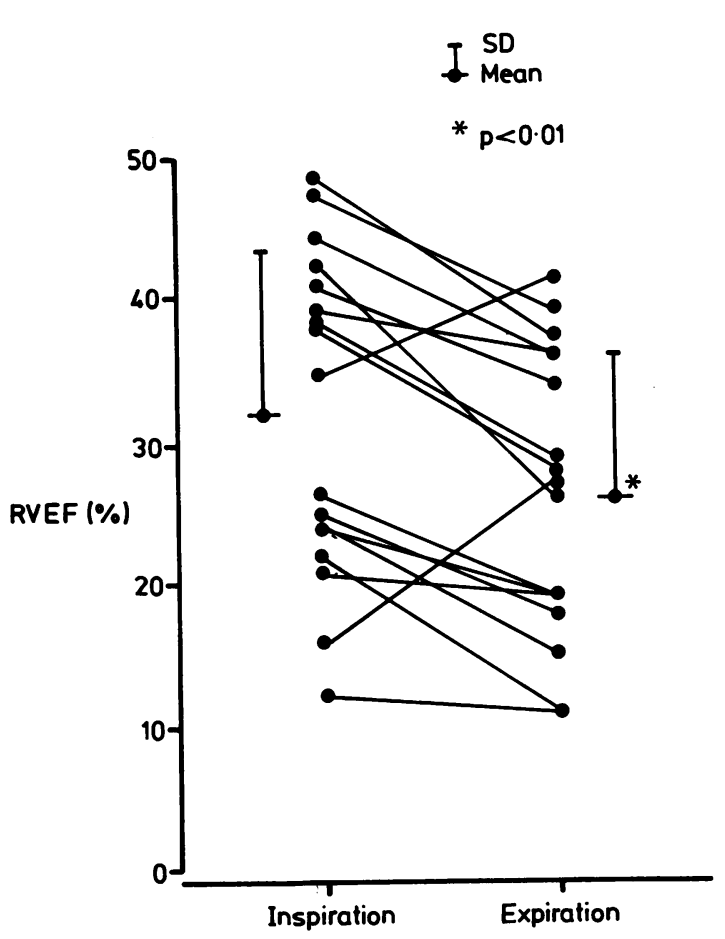

Fig 2 Right ventricular ejection fractions on inspiration (left) and expiration in all 17 subjects (mean (SD)). $R V E F$, right ventricular ejection fraction. was $11-41 \%$ with a mean of $26.2(9.9) \%$ (p $<0.01 v$ inspiration). In the whole group the change from inspiration to expiration was $-5.7(6.5) \%$. Fifteen of 17 individuals showed a fall in ejection fraction from inspiration to expiration ranging from 1 to $16 \%$, with a mean $7 \cdot 7(3 \cdot 8) \%$. Two subjects showed a rise of $6 \%$ and $11 \%$ respectively.

Figure 3 shows the distribution of changes in right ventricular ejection fraction from inspiration to expiration. This confirms that most individuals had a fall in ejection fraction, with a normal distribution around a median value of $-7 \%$. The $99 \%$ probability limits for the mean value are -10.3 to $-1.1 \%$ indicating a high probability that these results represent a true fall in ejection fraction.

Table 1 shows the mean (SD) results for all individuals for the bolus duration, right ventricular ejection fraction, right ventricular cycles, right ventricular transit time, and heart rate. These are shown for inspiration, expiration, and the difference between these values. As shown in figure 2, there is a significant fall in ejection fraction, but there are no other significant differences.

\section{CHANGES FROM REST TO THE VALSALVA MANOEUVRE}

Figure 4 shows the change in right ventricular ejection fraction from rest to the Valsalva manoeuvre in eight subjects. The right ventricular ejection fraction increased from $29 \cdot 4(7 \cdot 3) \%$ (range $20-38 \%$ ) 


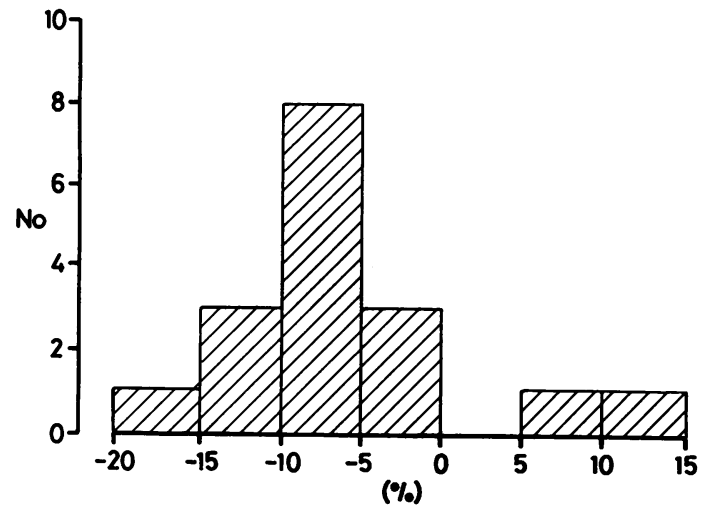

Fig 3 Distribution of changes in right ventricular ejection fraction from inspiration to expiration.

at rest to $42.6(9.6) \%$ (range $25-54 \%$ ) during the Valsalva manoeuvre $(p<0.001)$. All subjects showed a rise (mean $13.3(6 \cdot 8) \%$, range $5-27 \%$ ).

Figure 5 shows the distribution of change in the ejection fraction from rest to Valsalva. The values are normally distributed around the mean.

Table 2 shows mean (SD) results in all the subjects of the bolus duration, right ventricular ejection fraction, right ventricular cycles, right ventricular transit time, and heart rate. In contrast with the inspiration/expiration results, bolus duration, right ventricular cycles, and right ventricular transit time were all significantly increased during the Valsalva manoeuvre. Heart rate was increased, and although this just fails to reach statistical significance it does suggest that imaging was performed during the strain phase of the Valsalva manoeuvre. ${ }^{18}$

Analysis of the changes in the bolus time-activity curve from rest to the Valsalva manoeuvre showed that six of the eight subjects had pronounced increases in bolus duration. In all these individuals pulsatile waves appeared during the Valsalva manoeuvre as shown in fig 1 . These were caused by oscillation of the bolus of radionuclide in the superior

Table 1 Changes from inspiration to expiration (mean $(S D))$

\begin{tabular}{|c|c|c|c|}
\hline Variable & Inspiration & Expiration & Difference \\
\hline $\begin{array}{l}\text { Bolus duration (s) } \\
\text { RVEF (\%) } \\
\text { RV cycles } \\
\text { RV transit time (s) } \\
\text { Heart rate }\end{array}$ & $\begin{array}{c}1 \cdot 3(1 \cdot 0) \\
31 \cdot 8(11 \cdot 2) \\
5(1 \cdot 5) \\
3 \cdot 7(1 \cdot 3)\end{array}$ & $\begin{array}{c}1 \cdot 5(0 \cdot 7) \\
26 \cdot 2(9 \cdot 9) \star \\
5 \cdot 8(2 \cdot 7) \\
4 \cdot 1(1 \cdot 8)\end{array}$ & $\begin{array}{l}0.1(1 \cdot 0) \\
-5 \cdot 7(6 \cdot 5) \\
0.8(2 \cdot 6) \\
0.4(1 \cdot 8)\end{array}$ \\
\hline (beats/min) & $76.5(12.8)$ & $79 \cdot 6(13 \cdot 1)$ & $3.1(6 \cdot 5)$ \\
\hline
\end{tabular}

${ }^{\star} \mathrm{p}<0.01$ inspiration $v$ expiration. EF, ejection fraction; $R V$, right ventricular.

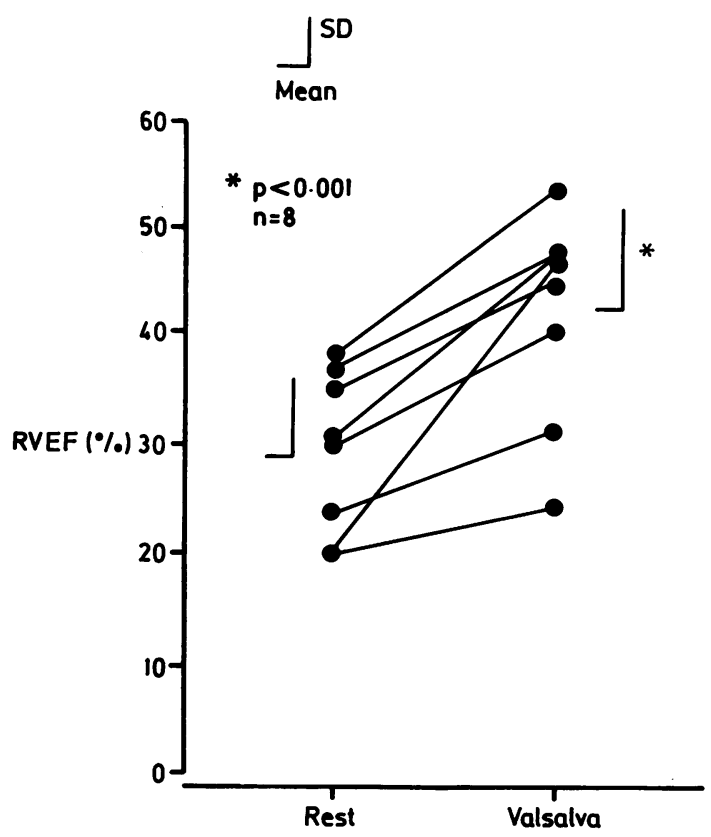

Fig 4 Right ventricular ejection fraction at rest (left) and during Valsalva manoeuvre in all eight subjects (mean (SD)). RVEF, right ventricular ejection fraction.

vena cava at a rate similar to the heart rate. These are suggestive, although not diagnostic of the development of tricuspid reflux, and, in our experience, are not seen in any other condition. A hold up of the passage of bolus for any other cause is not associated with regular pulsatile changes in the time-activity curve.

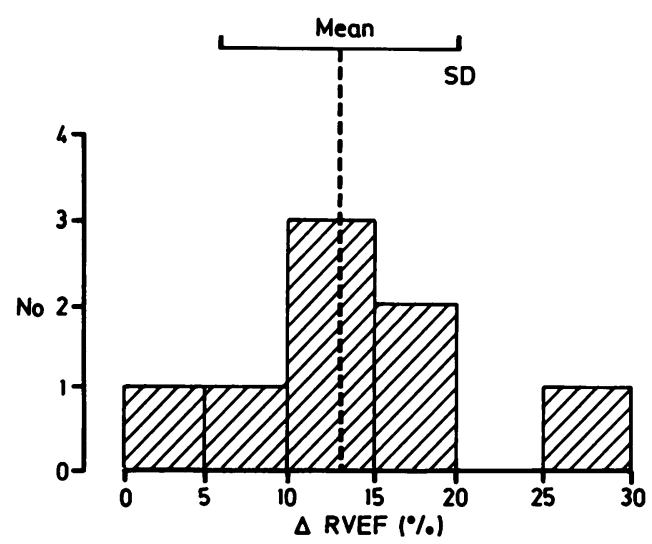

Fig 5 Distribution of changes in right ventricular ejection fraction from rest to Valsalva manoeuvre. $R V E F$, right ventricular ejection fraction. 
Table 2 Changes from rest to Valsalva manoeuvre (mean $(S D)$ )

\begin{tabular}{|c|c|c|c|}
\hline Variable & Rest & Valsalva & Difference \\
\hline $\begin{array}{l}\text { Bolus duration (s) } \\
\text { RVEF (\%) } \\
\text { RV cycles } \\
\text { RV transit time (s) } \\
\text { Heart rate }\end{array}$ & $\begin{array}{r}0.9(0.2) \\
29.4(7.3) \\
4.1(1.0) \\
3.3(0.9)\end{array}$ & $\begin{array}{c}2 \cdot 8(1 \cdot 8)^{\star} \\
42 \cdot 6(9 \cdot 6)^{\star \star} \\
7 \cdot 8(4 \cdot 0)^{\star} \\
5 \cdot 3(2 \cdot 3)^{\star}\end{array}$ & $\begin{array}{r}1.9(1.8) \\
13.3(6.8) \\
3.6(3.5) \\
2.0(1.8)\end{array}$ \\
\hline (beats/min) & $67 \cdot 1(14 \cdot 7)$ & $81 \cdot 8(17 \cdot 8)$ & $14 \cdot 6(19 \cdot 9)$ \\
\hline
\end{tabular}

${ }^{\star} \mathrm{p}<0.05,{ }^{\star \star} \mathrm{p}<0.001$. Same abbreviations as table 1 .

\section{Discussion}

METHODS OF ASSESSING RESPIRATORY CHANGES IN RIGHT VENTRICULAR FUNCTION

Radionuclide angiography has several advantages over other methods of studying the right ventricle. It is non-invasive, does not induce arrhythmias and does not require assumptions about the right ventricle's complex geometric shape. In gated studies ${ }^{24}$ overlap by other chambers may be a problem, and the time required for data acquisition means that rapid changes will be missed. It would be difficult, if not impossible, to perform gated studies to assess the respiratory changes in right ventricular function because of this. Echocardiography, although noninvasive and having good spatial resolution, has the inherent disadvantages that the assessment of changes in right ventricular volume requires both assumptions about ventricular shape and good imaging in at least two planes. ${ }^{1920}$ Since during respiration there is movement of the heart it is difficult to locate the same planes at different phases of the respiratory cycle. Thus first pass radionuclide angiography is uniquely suited to the study of rapid changes in right ventricular function, and the use of gold-195m means that multiple rapid studies may be performed with a low radiation burden. ${ }^{21}$

\section{CHANGES WITH RESPIRATION}

This study showed that right ventricular ejection fraction falls from maximal inspiration to expiration by, on average, about $6 \%$. This is not unexpected because venous return, and therefore right ventricular preload, falls and afterload increases during expiration. The radionuclide assessment of right ventricular ejection fraction correlates well with haemodynamic measures of right ventricular function, particularly mean pulmonary artery pressure and to some extent right ventricular filling pressure. ${ }^{22}$ But radionuclide angiography is sensitive enough to show the changes in right ventricular ejection fraction that accompany respiratory induced changes in haemodynamic function. Since the mean ejection fraction on inspiration was about $30 \%$, a fall of about $6 \%$ represents an average overall $20 \%$ fall in ejection fraction. Impaired atrial filling and increased intrathoracic pressure on maximal expiration did not significantly prolong either the bolus duration or the right ventricular transit time.

\section{CHANGES DURING THE VALSALVA MANOEUVRE}

In the second part of the study we assessed the effects of the Valsalva manoeuvre on right ventricular function. The strain phase of the Valsalva manoeuvre caused a fall in left ventricular volume and ejection fraction. ${ }^{18}$ Echocardiographic studies that use the right ventricular area, a measure that correlates well with right ventricular volume, have shown falls of up to $70 \%$ in right ventricular end diastolic volume, associated with maintenance of or only a slight reduction in stroke volume. ${ }^{10}$ Since the ejection fraction is calculated from stroke volume divided by end diastolic volume this should increase during the Valsalva manoeuvre.

Our data suggest that this may well be so, because there was on average a $45 \%$ increase in right ventricular ejection fraction from rest to the Valsalva manoeuvre. In contrast with the study of inspiration and expiration there was significant prolongation of both inflow to the right ventricle, as measured by bolus duration, and right ventricular transit time. Qualitative assessment of the bolus curves from the superior vena cava showed them to have a pulsatile element that is characteristic of tricuspid regurgitation. It is difficult to be certain that this feature really did reflect tricuspid reflux because the increase in right ventricular pressure might simply result in bolus hold up. However, in our experience, it is unusual to see these pulsatile waves in individuals with raised right sided pressures, but they often occur in patients with tricuspid regurgitation. We have previously shown that prolongation of bolus duration in itself has no effect on the calculated right ventricular ejection fraction, ${ }^{15}$ so that the changes we saw in right ventricular ejection fraction during the Valsalva manoeuvre are unlikely to be related to this variable. Using the first pass technique we were unable to assess right ventricular volume, but the finding of increased right ventricular ejection fractions combined with data suggesting reduced forward flow in the pulmonary artery, ${ }^{9}$ indicates an explanation for the apparent paradox of tricuspid regurgitation associated with reduced right ventricular end diastolic volumes. Thus it may be that right ventricular ejection fraction increases during the Valsalva manoeuvre despite increased afterload and reduced end diastolic volume because blood is ejected into the venous system via a regurgitant tricuspid valve. This hypothesis would fit the 
observed data, but further study is required to quantify the extent of the tricuspid regurgitation.

Finally, is it possible that the changes in right ventricular ejection fraction might also, in part, be caused by changes in heart rate or contactility. Heart rate increased, but not significantly from rest to the Valsalva manoeuvre. Studies of the relation between heart rate and left ventricular ejection fraction showed that over the physiological range, changes in heart rate do not significantly affect ejection fraction, and above this range the direction of change in ejection fraction, a fall with increased heart rate, is in the opposite direction to the changes that we found during the Valsalva manoeuvre. ${ }^{23}$ The change in heart rate in the current study was $<40$ beats $/ \mathrm{min}$ in all cases and it seems unlikely that heart rate alone would explain the difference in right ventricular ejection fraction from rest to the Valsalva manoeuvre. In addition the change in heart rate might reflect the change in inotropic state and hence contractility; but data from left ventricular studies again suggest that in the range of heart rates studied this is unlikely to be so. ${ }^{24}$ It seems unlikely that the changes we saw in right ventricular ejection fraction are related to changes in heart rate or contractility; they are more likely to reflect changes in loading conditions.

\section{CONCLUSIONS AND CLINICAL IMPLICATIONS}

These data suggest that the right ventricular ejection fraction, derived from first pass radionuclide angiography, is a sensitive method of assessing changes in right ventricular function during respiratory manoeuvres, and that the ejection fraction falls on maximal expiration and rises during the strain phase of the Valsalva manoeuvre. The clinical implications of these findings are unclear, but they do suggest that changes in right ventricular ejection fraction at peak exercise may, in part, be related to respiration, since rapid deep breathing occurs during exercise. These data may explain why the response of right ventricular ejection fraction to exercise is the same in normal individuals and in those with coronary artery disease and pulmonary disease. ${ }^{25-27}$ They also imply that changes in right ventricular function on exercise, assessed by first pass studies in individuals with coronary disease, may not simply reflect right ventricular ischaemia. ${ }^{26}$ It could be that respiratory manoeuvres may be of use as a test of right ventricular "functional reserve" in the assessment of patients with isolated right ventricular myopathies and in those with overt pulmonary disease in whom exercise studies are difficult, but as yet there are no data on this aspect.

JLC was supported by the British Heart Foundation.

\section{References}

1 Cohn JN, Guiha NH, Broder MI, Limas CJ. Right ventricular infarction: clinical and haemodynamic features. Am J Cardiol 1974;33:209-44.

2 Maddahi J, Berman DS, Matsouka DT, et al. A new technique for assessing right ventricular ejection fraction using rapid multiple-gated equilibrium cardiac blood pool scintigraphy. Circulation 1979; 60:581-9.

3 Harolds JA, Grove RB, Bowen RD, Powers TA. Right ventricular function as assessed by two radionuclide techniques. J Nucl Med 1981;22:113-5.

4 Legrand V, Chevign M, Foulon J, Rigo P. Evaluation of right-ventricular function by gated blood pool scintigraphy. J Nucl Med 1983;24:886-93.

5 Hurwitz RA, Treves S, Kurac A. Right and left ventricular ejection fraction in paediatric patients with normal hearts: first pass radionuclide angiocardiography. Am Heart J 1983;107:726-32.

6 Dymond DS, Elliot AT, Flatman W, et al. Clinical validation of gold-195m: a new short half-life radiopharmaceutical for rapid sequential first-pass angiocardiography in man. J Am Coll Cardiol 1983;2: 85-92.

7 Schlant RC. Normal physiology of the cardiovascular system. In: Hurst JW, ed. The heart. New York: McGraw Hill, 1978:71-100.

8 Benza GC, Mantero O, Marzegalli M, Morbelli E, Rampulla C, Morpurgo M. Simultaneous right and left heart catheterization and transmural pressure in chronic obstructive lung disease. Prog Resp Res 1975;9:55-62.

9 Wilkinson PL, Stowe DF, Tyberg JV, Parmley WW. Pressure and flow changes during Valsalva-like manoeuvers in dogs following volume infusion. $\mathrm{Am} \mathrm{J}$ Physiol 1977;233:H93-9.

10 Little WC, Barr WK, Crawford MH. Altered effect of the Valsalva manoeuver on left ventricular volume in patients with cardiomyopathy. Circulation 1985;71: 227-33.

11 Dymond DS, Jarritt PH, Britton KE, Spurrell RAJ. Detection of postinfarction left ventricular aneurysms by first pass radionuclide ventriculography using a multicrystal gamma camera. Br Heart $J$ 1979;41: 68-78.

12 Elliot AT, Dymond DS, Stone DL, et al. A mercury$195 \mathrm{~m} /$ gold-195m generator for use in first pass nuclear angiocardiography. Phys Med Biol 1983;28: $139-47$.

13 Ferlinz J. Measurement of right ventricular volumes in man from single-plane cineangiograms. Am Heart J 1977;94:87-90.

14 Zema MJ, Restivo B, Sos T, Sniderman KW, Kline S. Left ventricular dysfunction-bedside Valsalva manoeuvre. Br Heart J 1980;44:560-9.

15 Caplin JL, Dymond DS, Flatman W, Camm AJ. The effect of bolus duration and injection rates on the measurement of right ventricular ejection fraction (RVEF) by first-pass radionuclide angiography (FPRA) using gold-195m [Abstract]. Clin Sci 1984; 67:42P.

16 Dymond DS, Grenier RP, Schmidt DH. Right 
ventricular ejection fraction from first-pass radionuclide angiograms: comparison with contrast right ventriculography [Abstract]. J Nucl Med 1981; 22:P23.

17 Dymond DS, Elliot A, Stone D, Hendrix G, Spurrell R. Factors that affect the reproducibility of left ventricular function from first-pass radionuclide ventriculograms. Circulation 1982;65:311-22.

18 Brooker JZ, Alderman EL, Harrison DC. Alterations in left ventricular volumes induced by Valsalva manoeuvre. Br Heart J 1974;36:713-8.

19 Levine RA, Gibson TC, Aretz T, et al. Echocardiographic measurement of right ventricular volume. Circulation 1984;69:497-505.

20 Wann SL, Stickles KR, Bamrah VS, Gross CM. Digital processing of contrast echocardiograms: a new technique for measuring right ventricular ejection fraction. Am J Cardiol 1984;53:1164-8.

21 Dymond DS, Caplin JL, Flatman W, Burnett P, Banim $S$, Spurrell R. Temporal evolution of changes in left ventricular function induced by cold pressor stimulation. An assessment with radionuclide angiography and gold 195m. Br Heart J 1984;51:557-64.
22 Korr KS, Gandsman AJ, Winkler ML, Shulman RS, Bough EW. Haemodynamic correlates of right ventricular ejection fraction measured with gated radionuclide angiography. Am J Cardiol 1982;49: 71-7.

23 Ricci DR, Orlick AE, Alderman EL, Ingels NB, Daughters GT, Stinson EB. Influence of heart rate on left ventricular ejection fraction in human beings. $\mathrm{Am}$ J Cardiol 1979;44:447-51.

24 Ricci DR, Orlick AE, Alderman EL, et al. Role of tachycardia as an inotropic stimulus in man. J Clin Invest 1979;63:695-703.

25 Johnson LJ, McCarthy DM, Sciacca RR, Cannon PJ. Right ventricular ejection fraction in patients with coronary artery disease. Circulation 1979;60:1284-91.

26 Olvey SK, Reduto LA, Stevens PM, Deaton WJ, Miller RR. First pass radionuclide assessment of right and left ventricular ejection fraction in chronic pulmonary disease. Chest 1980;78:4-9.

27 Matthay RA, Berger HJ, Davies RA, et al. Right and left ventricular exercise performance in chronic obstructive pulmonary disease: radionuclide assessment. Ann Intern Med 1980;93:234-9. 